\title{
Nação, região e a unidade nacional uma leitura baseada em dois livros didáticos de história publicados na Primeira República*
}

\author{
CRISTIANI BERETA DA SILVA \\ Universidade do Estado de Santa \\ Catarina, Florianópolis, SC, Brasil
}

RESUMO

Este artigo objetiva discutir os sentidos de nação e região e a questão da unidade nacional presentes nos discursos sobre a história do Brasil e a história de Santa Catarina, construídos e divulgados na Primeira República. A proposta é analisar dois livros destinados ao público escolar: História do Brasil. Curso Superior, de João Ribeiro, publicado em 1900; e Pequena história catarinense, de Lucas Alexandre Boiteux, de 1920, com base em seu contexto de produção e circulação. A história e a geografia serviram ao propósito de legitimação das fronteiras estabelecidas entre os estados, assim como o da construção de um passado e tradição comuns que destacassem as especificidades de cada região e respectiva contribuição para a grandeza da nação. Espera-se contribuir para evidenciar as bases políticas sobre as quais se assentaram as histórias regionais no passado em relação à história do Brasil, bem como para adensar o debate sobre a produção didática de história regional no presente.

\section{PALAVRAS-CHAVE}

nação; região; livros didáticos.

* Uma primeira versão deste artigo foi apresentada no Grupo de Trabalho História da Educação (GT02), na 35a Reunião Anual da Associação Nacional de Pós-Graduação e Pesquisa em Educação (ANPEd), em outubro de 2012. Agradeço a leitura crítica das professoras Maria Teresa Santos Cunha, Luciana Rossato, Nucia Alexandra Silva de Oliveira, do professor Rogério Rosa Rodrigues e dos/as estudantes Marcos Luã de Freitas, Lara Rodrigues, Caroline Alamino, Flávio Welker Merola Gentil e Iara Steiner. 


\title{
NATION, REGION AND NATIONAL UNITY: A READING \\ OF TWO HISTORY TEXTBOOKS PUBLISHED \\ DURING THE FIRST BRAZILIAN REPUBLIC
}

\begin{abstract}
This article aims to discuss the meanings of nation and region, as well as the issue of national unity, present in the discourses on the Brazilian history and Santa Catarina state history. Such discourses were constructed and disseminated during the First Brazilian Republic (1889-1930). To this end, we have analyzed two textbooks - História do Brasil. Curso Superior (Ribeiro, 1900); and Pequena bistória catarinense (Boiteux, 1921) - considering their respective contexts of production and circulation. Both history and geography served not only to legitimate state borders, but also to construct a common past and tradition which highlighted the specificities of each region and their respective contributions to national growth and progress. We expect this article to contribute to bringing to light the political bases upon which regional histories in the past settled in relation to the Brazilian history, as well as to strengthening the debate on the current production of regional history textbooks.
\end{abstract}

KEYWORDS

nation; region; textbooks.

\section{NACIÓN, REGIÓN Y UNIDAD NACIONAL: UNA LECTURA A PARTIR DE DOS LIBROS DIDÁCTICOS DE HISTORIA PUBLICADOS EN LA PRIMERA REPÚBLICA}

\section{RESUMEN}

Este artículo tiene como objetivo discutir los sentidos sobre nación y región y la cuestión de la unidad nacional, presentes en los discursos sobre la historia de Brasil y la historia de Santa Catarina construidos y difundidos en la Primera República. Se propone analizar, a partir de su contexto de producción y circulación, dos libros destinados al público escolar: História do Brasil. Curso Superior, de João Ribeiro, publicado en 1900; y Pequena história catarinense, de Lucas Alexandre Boiteux, de 1921. La historia y la geografía sirvieron al propósito de la legitimación de las fronteras establecidas entre los estados, así como de la construcción de un pasado y tradición comunes que pusieron en relieve las especificidades de cada región y la respectiva contribución para la grandeza de la nación. Se espera contribuir para evidenciar las bases políticas sobre las que se asentaron las historias regionales en el pasado con relación a la historia de Brasil, y también para incrementar el debate sobre la producción didáctica de historia regional en el presente.

\section{PALABRAS CLAVE}

nación; región; libros didácticos. 


\section{APRESENTAÇÃO}

A escrita da história é uma operação marcada primeiramente pela particularidade do lugar de quem escreve. Entre outras marcações, sejam elas simbólicas ou não, essa é capital. Michel de Certeau (1982) é quem não deixa os historiadores esquecerem que existe uma historicidade da história, um movimento que liga uma prática interpretativa a uma prática social. São as escolhas do historiador que ligam as ideias aos lugares, numa operação marcada por três fases: seleção de fontes, procedimentos de análise e escrita da história (idem,p. 66). Com base nesses pressupostos, explicitar as escolhas realizadas é uma maneira de indicar as possibilidades e os limites deste artigo, que objetiva discutir questões relacionadas às ideias de nação e região e a questão da unidade nacional, presentes nos discursos sobre a história do Brasil e de Santa Catarina, construídos e divulgados no início do século XX. Tal proposta será aqui desenvolvida com base na análise de dois livros destinados ao público escolar: História do Brasil. Curso superior, de João Ribeiro (1860-1934), publicado em 1900, ${ }^{1}$ e Pequena história catarinense, ${ }^{2}$ de Lucas Alexandre Boiteux (1880-1966), de 1920.

Essa escolha confere a esses livros poder e os torna documentos/monumentos (Le Goff, 2003), e nessa condição não devem ser analisados isoladamente do conjunto de monumentos do qual fazem parte. Por essa razão, a análise empreendida levará em conta o contexto de produção desses livros, sua autoria e elementos partilhados por ambos os autores quanto à preocupação com a unidade nacional.

Os livros foram selecionados não pelas questões que os afastam ou os aproximam de métodos, estilos e conteúdos, e sim pelo contexto político de instalação do regime republicano, que colocou em pauta não apenas a necessidade de redefinir a identidade nacional, mas também de ensiná-la. Contudo, explicar o Brasil naquele momento implicava incorporar as histórias genericamente chamadas de regionais ao conjunto nacional. As chaves de leitura utilizadas envolvem interpretações sobre as representações de nação e de região nos discursos da época, representações estas que marcam a história do Brasil e a de Santa Catarina escritas por João Ribeiro e Lucas Boiteux. Produtos de um determinado tempo e lugar, esses livros fornecem aspectos simbólicos que indicam as posições e os interesses assumidos pelos autores, a forma como viam e descreviam o Brasil, como pensavam que ele era, ou como

1 Neste artigo foram utilizadas duas edições: uma segunda edição publicada pela Livraria Cruz Coutinho, em 1901, e uma décima oitava, revista e completada por Joaquim Ribeiro (filho de João Ribeiro), publicada pela Livraria Francisco Alves em 1964. Ambas as edições eram destinadas ao curso superior, ou seja, à época, destinavam-se aos alunos dos últimos anos do secundário que pretendiam prestar exames de acesso às faculdades do país (Melo, 2008, p. 24).

2 Está sendo considerada também a edição História de Santa Catarina. Resumo didático, publicada pela Editora Melhoramentos em 1930, por ser a versão atualizada e de abrangência nacional do livro Pequena história catarinense. Cumpre informar que, com o objetivo de facilitar a leitura, optou-se por atualizar a grafia dos livros e dos documentos citados, seguindo as atuais normas ortográficas da língua portuguesa. 
gostariam que ele fosse. Do mesmo modo, indicam as relações estabelecidas com a cultura política daquele momento, haja vista que esta se "inscreve no quadro das normas e dos valores que determinam a representação que uma sociedade faz de si mesma, do seu passado, do seu futuro" (Berstein, 1998, p. 353).

Ambos os autores, produtos do período de ambiguidades e complexidades que marcaram a transição do século XIX para o século XX, faziam parte de um seleto grupo de homens públicos e letrados que viveram e atuaram profissionalmente na Primeira República. Neste artigo, esses homens são identificados como intelectuais, mesmo a despeito da falta de consistência teórica e empírica capaz de subsidiar a separação da atuação do intelectual da atuação do político no período abordado (Gomes, 2010). Isso porque, acompanhando Ângela de Castro Gomes (idem, p. 147-148), pode-se identificar que esses sujeitos eram produtores de bens simbólicos, de interpretações da realidade social de grande valor político, definidos pela propriedade de capital cultural e envolvidos direta ou indiretamente na arena política.

A instalação de um novo regime político veio exigir a redefinição do projeto de nação. Outros marcos explicativos foram necessários para a escrita da história do Brasil. Compreende-se que os livros e autores selecionados para esta discussão fornecem indícios de como a identidade brasileira estava sendo redesenhada e como o problema da unidade nacional estava sendo enfrentado. Deve estar claro, contudo, que nenhum texto mantém uma relação direta com a realidade que apreende, com as práticas que designa. Roger Chartier $(2002$, p. 63) chama a atenção para o fato de que um texto, seja ele literário ou documental, é antes de tudo uma construção que possui "categorias, esquemas de percepção e de apreciação, regras de funcionamento que remetem para as suas próprias condições de produção". As questões que os livros de Ribeiro e Boiteux apresentam como reais foram construídas tendo como referentes os modelos discursivos e as delimitações intelectuais que circunscreviam os autores e suas ideias. "O real assume assim um novo sentido: aquilo que é real, efetivamente, não é (ou não é apenas) a realidade visada pelo texto, mas a própria maneira como ele a cria, na historicidade da sua produção e na intencionalidade da sua escrita" (idem, ibidem).

Homens de seu tempo, Ribeiro e Boiteux tomaram para si a responsabilidade de escrever e divulgar a história, atribuindo-lhe um valor pedagógico de formação para a cidadania. Envolvidos nos debates sobre a identidade nacional, certamente partilharam - em suas diferenças, considerando as singularidades próprias da existência particular de cada um - valores e sentidos atribuídos à noção de nação e região, bem como se preocuparam, assim como os demais intelectuais de sua geração, em buscar conhecer e explicar o Brasil e quem eram os brasileiros. Para tanto, era necessário estabelecer o que era comum e o que era diferente e singular, bem como definir os novos "outros" em relação à ideia de nação que se forjava naquele momento. Isso porque a definição ou redefinição de um projeto de nação precisa levar em conta os duplos desse processo, ou seja, em relação a qual "outro" o projeto de construção da nacionalidade será materializado? Quais sujeitos individuais ou 
coletivos e quais ideias farão parte desse projeto comum? Quais serão excluídos? Essas questões deram o tom da construção dos sentidos de nação e de região naquele momento histórico.

\section{A ESCRITA DA HISTÓRIA DO BRASIL E JOÃO RIBEIRO}

Mal comparando, espremido no colarinho em pé, parecia uma parafimosis. Tinha a expressão severa e imóvel. Cenho cerrado, sulcos nasolabiais profundos, boca fendida duramente e lábio inferior ligeiramente protuso. Dentes feios, mas tratados. Nariz redondo. Expressão pouco móvel, mas extraordinariamente avivada pelos olhos negros sempre em movimento. Só a face era inexpressiva, os olhos compensavam. Uma vez ensaiou o bigode e ficou com cara de órgão genital. Raspou-o e tornou a dar decência à fisionomia. Nem alto, nem baixo. Mais para magro do que gordo. Só umas banhinhas mal distribuídas, de velho. Vestia-se limpamente, mas mal e desleixadamente. Parecia tudo comprado na Casa Rolas. Vimo-lo, um dia, de fraque. Três casas e um botão. Ousamos interpelá-lo. Era quinta-feira e dia de Academia. Andava deselegantemente. Ao trocar os passos, quando assentava no chão o pé rompente, fazia um movimento de quadris para a frente como se quisesse adiantar as partes. Já se disse que no seu modo de escrever, ele é quem nos libertou de Portugal. Foi assim um pré-modernista e daí sua simpatia pelo movimento. (Nava, 2001, p. 255)

O passado tornado presente pela memória é poderosamente imaginativo. Pois, embora o passado - para os historiadores - tome forma com base em vestígios, ele comumente é escrito e narrado pela imaginação (Ricoeur, 2010, p. 139). Foi recompondo vestígios das suas lembranças que Pedro Nava descreveu João Ribeiro, seu professor de história universal no Colégio Pedro $\mathrm{II}^{3}$ em 1919 e de história do Brasil em 1920. A escrita de Nava dispensa apresentações, e o João Ribeiro que nos chega por meio de suas memórias ganha contornos, se não mais reais, ao menos mais primorosos, bem-humorados. O João Ribeiro que toma forma nessa descrição é um professor respeitado, pois ilustríssimo. Admirado como "homem das letras", mas não propriamente como "dador de aulas", professor, no sentido atribuído por Pedro Nava, pois nessa condição ele "era extremamente displicente. E tinha razão. Só no Brasil, um homem daquela classe e daquela estatura ficava vegetando entre jovens malandros do ginásio" (Nava, 2001, p. 253). Se como professor Ribeiro era

3 Neste artigo, optou-se por usar sempre a denominação Colégio Pedro II, independentemente do período. Destaca-se, porém, que o colégio sofreu alterações tanto em relação à sua denominação de fundação - Imperial Colégio de Pedro II - quanto às suas linhas educacionais ao longo do tempo, sendo as mais marcantes aquelas sofridas com a mudança do regime. Com a República, entre outras determinações, o nome do colégio foi, de imediato, alterado para Ginásio Nacional. A antiga denominação retorna, porém, em 1911, como Colégio Pedro II (Gasparello, 2004). 
displicente, Nava não deixa de atestar o reconhecimento e legitimação alcançados em sua condição de autor, divulgador da história do Brasil:

Aprendíamos muito mais nos livros do nosso mestre como leitura de repouso nas longas horas vagas ou nas longuíssimas dos estudos da manhã e da noite que com ele próprio. Mas ele estava nos livros... Folheá-los era folheá-lo... (idem, ibidem)

O João Ribeiro das lembranças de Nava já contava com seus 59 anos, lá pelos idos de 1919. Nascido em Laranjeiras (SE), em 1860, mudou-se para o Rio de Janeiro em 1881 e começou a trabalhar como professor. Em 1887, fez concurso para a cadeira de português do Colégio Pedro II, mas sua nomeação, em 1890, foi para a cadeira de história universal e do Brasil. Ensinou história por mais de três décadas no Colégio Pedro II e na escola normal e foi, portanto, como professor de história do Brasil, e já reconhecido como filólogo e autor de livros, principalmente sobre a língua nacional, que ele lançou em 1900 - no simbólico ano do quarto centenário do Descobrimento do Brasil - o livro História do Brasil. ${ }^{4}$

Desde o lançamento, o livro alcançou um êxito inesperado, sendo adaptado, ainda em 1900, para duas edições separadas: uma para o nível primário, outra para os cursos superiores. As primeiras edições foram feitas inicialmente pela Livraria Cruz Coutinho, de Jacintho Ribeiro dos Santos, mas as edições mais conhecidas seriam publicadas pela Livraria Francisco Alves, na qual João Ribeiro se converteria num dos autores editados mais importantes (Hallewell, 2005).

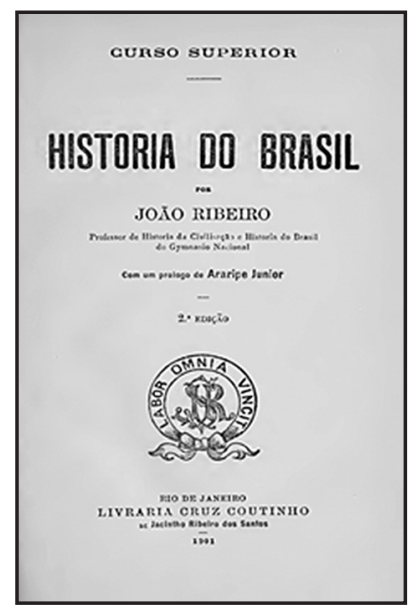

Figura 1 - Capa do livro História do Brasil, (2. ed., 1901).

Fonte: Acervo pessoal da autora.

Elaboração da autora.

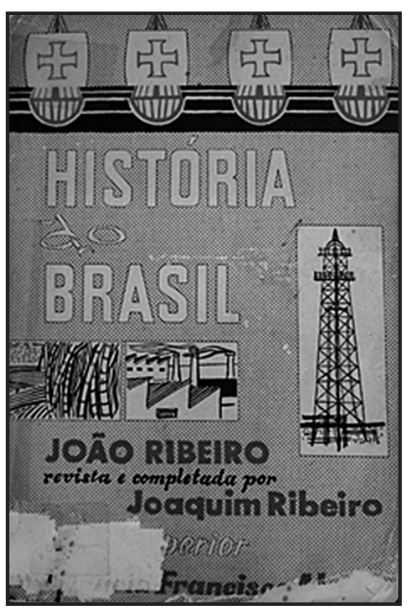

Figura 2 - Capa do livro História do Brasil (18.ed., 1966).

Fonte: Acervo pessoal da autora. Elaboração da autora.

4 Essas informações foram sintetizadas tomando-se por base os trabalhos de Gasparello (2004), Hansen (2000) e Melo (2008). 
Em sua escrita, Ribeiro identificou duas correntes cujos elementos seriam centrais na formação do Brasil: a história local e a história comum. Ao encadear esses elementos e elegê-los como formadores da nação, ele atenderia a uma necessidade já há muito debatida: responder à questão de "quem somos". Tal necessidade precisa ser lida no interior da relação que configurou a própria ideia de Estado-nação. Não existe nação sem sentimento nacional, e este é idealizado antes da invenção das nações, no sentido de que estas "não formam os Estados e os nacionalismos, mas sim o oposto" (Hobsbawm, 1990, p. 19). Definir a identidade nacional era uma necessidade datada, situada na invenção do Brasil por intermédio da escrita de sua história como nação independente.

No século XIX, foi o Instituto Histórico e Geográfico Brasileiro (IHGB) que chamou para si a responsabilidade de escrever e divulgar a história nacional. Desde sua fundação, a preocupação com as "histórias provinciais" se fez presente entre os sócios e aparecia justamente nas discussões relativas à unidade territorial. Afinal, os movimentos espraiados das províncias indicavam risco à ordem interna, pois as ambições descentralizadoras e/ou desagregadoras de algumas províncias colidiam com a univocidade do tratamento da nacionalidade. Os membros do instituto, capitaneados por Januário da Cunha Barbosa, assumiram a missão de resolver o problema da unidade nacional diante das diferentes histórias que formavam o ainda arquipélago chamado Brasil. Desse modo, desde a fundação do IHGB, embora houvesse divergências, o vínculo das províncias com a nacionalidade foi enfatizado por força do discurso (Lazzari, 2004; Melo, 2008). Os fatos provinciais considerados significativos e importantes deveriam se tornar elementos do passado nacional comum, servindo ao propósito de consolidação do Brasil como Estado territorial moderno. Os discursos produzidos com base nessa lógica certamente iriam contribuir para a definição de nação e região na produção historiográfica brasileira.

Manuel Luís Salgado Guimarães (1988) lembra que a definição da identidade brasileira construída pelos membros do IHGB nesse período não foi feita em oposição à antiga metrópole portuguesa, mas sim seguindo o pressuposto de que a nova nação continuaria o processo civilizador instaurado pela colonização portuguesa. Nação, Estado e Monarquia aparecem como elementos de unidade nacional construída em relação a um "outro", tanto no plano interno quanto no externo. Essa definição de nação brasileira elegeu, no plano externo, as repúblicas latino-americanas como alvo da oposição, pois representavam risco à estabilidade política. No plano interno, as províncias acabaram se constituindo num "outro" importante para operar o conceito de nação. Da mesma forma, nesse projeto eminentemente excludente, as populações indígenas e negras ficavam de fora, "por não serem portadoras da noção de civilização" (idem, p. 7).

A proposta de uma escrita de história do Brasil para resolver o "problema das três raças" - conquanto não retirasse do branco seu lugar de portador privilegiado de civilidade -, bem como o "problema das províncias", foi apresentada pelo naturalista alemão Karl Friedrich Philipp von Martius, na década de 1840. Vencedor 
do concurso promovido pelo IHGB, sobre como a história do Brasil deveria ser escrita, ele enfatizou em sua monografia:

Em primeiro lugar, seja em épocas, judiciosamente determinadas, representando o estado do país em geral, conforme o que tenha de particular em suas relações com a Mãe Pátria, e as partes do Mundo; e que, passando logo para aquelas partes do país que essencialmente diferem, seja realçado em cada uma delas o que houver de verdadeiramente importante e significativo para a história. (Martius, 1845, p. 399)

Em outras palavras, a escrita da história de uma determinada região precisaria significar, antes de tudo, a escrita da história do Brasil. A proposta de Martius repercutiu significativamente na produção historiográfica nacional. Sua "história do Brasil" acabou por fornecer um modelo para os historiadores que representariam o Brasil em seus escritos a partir de então, mesmo para aqueles que não concordavam com todos os princípios por ele defendidos, como a Monarquia, por exemplo.

Ao comparar as obras de Joaquim Manuel de Macedo e João Ribeiro, o historiador Bandeira de Melo (2008) observa que o primeiro, com a tutela de Francisco Adolfo de Varnhagen, procurou divulgar - pela via da escola, especificamente no Colégio Pedro II, e pelo manual Liçôes de história do Brasil $-{ }^{5}$ que os fatos regionais serviam à unidade nacional. Apenas a unidade seria capaz de ligar o país à civilização, pois ela definiria a formação da nação (idem, p. 38). Mas certamente foi João Ribeiro quem soube melhor incorporar essa perspectiva, no julgamento de que ele "compreendeu bem os rumos orientadores de Martius" (idem, p. 212), mesmo que tenha tentado minimizar sua influência, como se pode acompanhar a seguir:

Do sentido em que se deve tratar a história interna, von Martius deu apenas indicações vagas e inexatas, mas caracterizou a multiplicidade de origens e de pontos de iniciação no vasto território; sem embargo da contestação de alguma crítica menos bem informada, fui o primeiro a escrever integralmente a nossa história segundo nova síntese. Ninguém, antes de mim, delineou os focos de irradiação da cultura e civilizamento do país; nenhum dos nossos historiadores ou cronistas seguiu outro caminho que o da cronologia e da sucessão dos governadores, caminho seguro mas falso em um país cuja história se fazia ao mesmo tempo por múltiplos estímulos em diferentes pontos. (Ribeiro, 1966, p. 22-23)

Importa destacar que esse trecho foi acrescido à introdução na terceira edição do livro História do Brasil, de 1908. Na segunda edição, de 1901, essa parte inexiste. É, portanto, uma reflexão posterior, provavelmente construída como resposta aos pares, após a circulação da obra, o que confirma sua repercussão entre os historiadores e demais intelectuais e indica a necessidade por parte do autor de demarcar $o$ ineditismo de sua escrita.

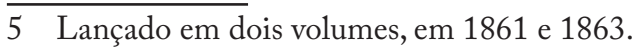


De todas as edições de História do Brasil, a destinada ao curso superior foi a que alcançou maior sucesso. Essa foi a versão adotada no secundário do Colégio Pedro II e também a que circulou em edições sucessivas até a década de 1960, conforme lembra Bandeira de Melo (2008, p. 17):

Quando fui prestar vestibular de direito em 1964 [...], a congregação da faculdade havia introduzido "História do Brasil" como disciplina do concurso e indicado como livro-texto História do Brasil - Curso Superior de João Ribeiro. Um manual cuja primeira edição é de 1900. A escolha foi justificada pelo fato de se tratar de edição atualizada (16 ${ }^{a}$ edição), ${ }^{6}$ do texto reeditado em 1960 , e o mais importante, que é congregação da faculdade: "era a melhor síntese de História do Brasil”. Boa parte daqueles professores (quase todos se aposentaram na compulsória) estudaram nossa "história pátria" pelo livro de Ribeiro.

A História do Brasil foi escrita com fins claramente didáticos, para uso do ensino de história, mas reverberou à época de modo bastante positivo no mundo intelectual da capital, Rio de Janeiro, chegando a círculos de intelectuais de outros lugares. O livro inaugurava uma série de novidades que já vinha fazendo parte da revisão da história nacional, mas que ainda não havia sido sintetizada por ninguém antes de Ribeiro. Esse "novo" não se refere apenas à explicação do Brasil, mas também às concepções de história e dos aspectos pedagógicos. Em se tratando das questões metodológicas, Patrícia Hansen (2000) destaca a impressão do texto em fontes (tipos) de tamanhos diferentes. A fonte maior destinava-se a expor as ideias gerais do livro e a questões de crítica histórica, e a menor, à narração da história. Tristão de Alencar Araripe Júnior (1901, p. X), que assina o prefácio da segunda edição da obra, valoriza essa estratégia como novidade pedagógica, indicando-a como "uma fase nova para o ensino de história no país". Segundo ele, as características didáticas possibilitariam que o manual fosse "carta de navegação pela qual o pior piloto pode levar o discípulo ao porto de destino" (idem, p. VII). Isso porque havia a disciplinarização do autor no tocante à leitura do aluno e à do professor:

O aluno só terá que ler do seu livro as narrações e fatos capitais da história nacional, o que se pode chamar a parte dramática dos acontecimentos; o mais fica a cargo do professor. O compêndio fornece todas as indicações que o devem induzir a estudar não somente a filosofia dos fatos, a sua filiação, e as interdependências geográficas, mas também a oportunidade de exibi-las e o modo consentâneo a cada aluno de despertar o interesse sobre eles, servindo-se das analogias que no ambiente próximo se oferecem como veículo da iniciação. Esta direção no compendio é dada ao mestre inteligente com o critério desejá-

6 Em pesquisa realizada na Biblioteca do Livro Didático (LIVRES) da Faculdade de Educação da Universidade de São Paulo (FEUSP), foi localizada a 19ª edição, de 1966. As três edições em tão curto espaço de tempo mais que indicam o sucesso e a pertinência da escrita da história do Brasil por João Ribeiro. 
vel, o que não o priva de modificá-la, de acordo com a crítica que cada professor tenha conseguido fazer sobre documentos originais. (Araripe Júnior, 1901, p. XII-XIII)

Além da questão metodológica, há ainda a abordagem da escrita da história. A organização da obra já evidencia o novo tratamento dispensado à explicação da história do Brasil. A formação do Brasil é dividida em duas partes: no quarto capítulo, a parte A, "A formação do Brasil - A história comum" (Ribeiro, 1901, p. 135-226), e no quinto capítulo a parte B, "A formação do Brasil - A história local" (idem, p. 227-263). Na introdução, Ribeiro justifica sua opção: "quis indicar, se me é permitida a expressão que acredito clara, as quatro células fundamentais que por multiplicação formaram todo o tecido do Brasil antigo" (idem, p. 19).

Hansen (2000) observa que o livro de João Ribeiro rompeu com a cronologia da "vida oficial", traço comum das "histórias do Brasil" publicadas até então. De forma importante, também Ribeiro apresenta uma perspectiva filosófica para essa história, buscando explicar o Brasil para além da formação do território e levando em conta a formação da nacionalidade e da cultura nacional. Ribeiro acrescenta o povo brasileiro à equação Estado-nação: um povo mestiço, incapaz de self- government (Ribeiro, 1901, p. 284), mas ainda assim um povo. A grandeza territorial do Brasil devia-se às ações desse povo que ocupou seu interior. Sua formação, sua identidade se dariam por meio de sua história comum e sua história local. As interações entre o Brasil "interno" o "externo" garantiam a manutenção da unidade nacional (Hansen, 2000, p. 93-94). A questão da unidade é também bastante destacada por João Ribeiro; sobre isso, Hansen (idem, p. 94) analisa que "esse espírito superior do unionismo" parece um pouco forçado em sua obra. Contudo, a ideia estava em circulação no Rio de Janeiro do autor: "Toda a pedagogia que atravessa o livro destacava a luta permanente dos elementos promotores da unidade contra a desagregação, cujo impulso parecia ser uma característica da 'psicologia' do povo brasileiro" (idem, ibidem).

A forma como Ribeiro escolheu organizar sua escrita, encadeando processos locais e aqueles considerados comuns, evidencia uma temporalidade diferente, não cronológica, mas relacional, numa ideia de movimento, processo. Evidência disso é a centralidade que a ideia de formação adquire no livro (idem). Aliás, Hansen observa que o conceito de formação começa a aparecer com mais frequência nos estudos históricos sobre o Brasil entre o final do século XIX e início do XX, indicando mudanças políticas e sociais no modo como o Brasil estava sendo percebido e pensado. Um novo regime político indicando mudanças, sugerindo a construção de um novo país, sobre outras bases, bem diferentes daquelas que sustentaram o regime imperial, fornece os indícios dessas mudanças e da ressignificação do conceito de formação. Isso porque "o conceito de 'formação' possui uma relação estreita com a categoria de tempo. Põe em evidência a temporalidade da constituição de um sujeito/objeto que ao final deverá adquirir determinada forma, sugerindo uma incompletude" (idem, p. 79). 
A opção por uma organização não linear da história, a explicação de um país e de um povo que considerasse as dimensões do seu interior e as particularidades das regiões, entre outros marcadores reconhecidos como novidades no livro de Ribeiro, são destacados não apenas pelos contemporâneos do autor, mas também por diferentes análises ao longo do tempo. Guy de Hollanda (1957, p. 122), por exemplo, ressalta a qualidade didática do livro, que, em sua avaliação, mesmo sem contar com ilustrações, não "oferecia dificuldades de leitura" aos alunos do curso secundário.

$\mathrm{Na}$ análise de Bandeira de Melo (2008), João Ribeiro assimilou as novas tendências projetadas pela revisão da história nacional desde a segunda metade do século XIX. Escreveu sua obra no entrecruzar complexo do fim de um século e início de outro, entre formas diferentes de perceber o mundo e o Brasil. O século XX e a República traziam promessas e compromissos com o novo, e "Ribeiro escreveu seu texto fundando-se nas tendências historiográficas em voga na segunda metade do séc. XIX, o historicismo alemão, e nos estudos antropológicos dominantes no Brasil" (idem, p. 24). Circe Bittencourt (2008, p. 160) salienta que muito provavelmente as inovações observadas na obra de Ribeiro são tributárias dos estudos feitos na Alemanha, onde ele permaneceu dois anos, "comissionado pelo governo".

Nesse livro, João Ribeiro apresentou uma interpretação inteiramente nova sobre o Brasil, ao incluir a história local e o "interior" em sua narrativa. A novidade de tal projeto nem havia sido incorporada aos programas de ensino de história do Brasil na década de 1930, conforme constata Guy de Hollanda (1957, p. 121): "até 1930, o programa da cadeira não teve em conta as ideias inovadoras de João Ribeiro, particularmente, com respeito à 'História Local' na formação do Brasil”.

A História do Brasil sintetiza a nação por meio da multiplicidade regional, da incorporação dos episódios internos "dos últimos confins", da ideia de um povo com identidade diferente daquela do colonizador:

O Brasil, o que ele é, deriva do colono, do jesuíta e do mameluco, da ação dos índios e dos escravos negros. Esses foram os que descobriram as minas, instituíram a criação do gado e a agricultura, catequizaram longínquas tribos, levando assim a circulação da vida por toda a parte até os últimos confins. Esta história, a que não faltam episódios sublimes ou terríveis, é ainda hoje a mesma presente, na sua vida interior, nas suas raças e nos seus sistemas de trabalho, que podemos a todo o instante verificar. (Ribeiro, 1901, p. 18)

O autor enfatiza os aspectos da história do interior do país, valoriza os regionalismos e os movimentos de povoamentos ligados às migrações, como no interior do Nordeste e do Sul, para melhor definir a formação nacional:

Ainda que sejam hoje numerosas as divisões administrativas do Brasil e ainda que a ação da monarquia brasileira lhes desse perfeita coordenação e unidade, a extensão geográfica e também a história das antigas capitanias confirmam a existência de grandes grupos locais em que se reparte a imensa área do país. (idem, p. 227) 
local.

Esses grupos possuiriam características próprias, formariam uma identidade

Cada um desses focos tem o seu sentimento característico; o da Bahia é o da religião e da tradição; o de Pernambuco é o radicalismo republicano e extremo de todas as suas revoluções; o de São Paulo (Minas e Rio) é o liberalismo moderado (aclamação de Bueno, a "províncias coligadas" que sustentaram a independência com a monarquia etc.); o da Amazônia, demasiado indiano, é talvez o da separação como o é no extremo sul o Rio Grande (a formação recentíssima), demasiado platino. (idem, p. 19)

Com Ribeiro, chama a atenção Arlette Medeiros Gasparello (2004, p. 173, grifos do original), "os conceitos de pátria e patriotismo passam a ter uma conotação mais ampla e sempre em referência à nação e à consciência dessa nação como pátria comum”. Mesmo que não trate do regime republicano recém-instaurado em seu livro, João Ribeiro deixa claro, em cada análise, sua condição de intelectual envolvido nesse processo político de transição e de promessas. Para ele, a unidade nacional ainda não fora alcançada pela Monarquia e seu poder centralizador.

Ainda hoje o Brasil ressente os gérmens das oligarquias locais que, como então, apenas toleram o protetorado do príncipe, vencedoras umas vezes, vencidas outras. Toda a nossa história é o desenvolvimento desse duelo original. Revezam-se cada século. As capitanias aparecem no século XVI; a união necessária pela guerra holandesa domina no século XVII; o espírito das capitanias volta de novo a emancipar-se no século XVIII, com as minas; a união com a monarquia subjuga-se no século XIX. Parece que o século XX se abrirá de novo para o particularismo federal. (Ribeiro, 1901, p. 43)

A Monarquia não constituiu uma nação, pois o sentido de nação para Ribeiro estava situado num outro princípio, segundo o qual somente a República e o sistema federalista seriam capazes de trazer unidade ao possibilitar a construção de uma identidade nacional. Talvez essa crítica de Ribeiro deva-se à circulação dos discursos com aspirações republicanas e liberais da época, que desde o final do século XIX sintetizavam a oposição "centralização-desmembramento" e "descentralização-unidade" como forma de consolidar a autonomia dos estados. Nesse mesmo caminho, as oligarquias regionais enfatizavam as diferenças culturais, econômicas e geográficas de cada região, entendidas como coincidentes com as divisões político-administrativas dos estados (Diniz Filho; Bessa, 1995, p. 28), no intuito de legitimar sua autonomia em relação ao poder central.

João Ribeiro, em seu tempo, observou a histórica local para além do recorte político-administrativo ao tratar dos grandes grupos locais que formaram o Brasil. "Esses são os núcleos primitivos do organismo nacional. Todos os demais são secundários e recentes. Se a federação fosse menos política e filosófica do que histórica, atender-se-ia a essa importante consideração" (Ribeiro, 1901, p. 19). 
Porém, mesmo atentando para essa importante questão, sua escrita da história do Brasil não rompeu com a relação hierárquica estabelecida entre a nação e a região, construída no âmbito do IHGB ainda na primeira metade do século XIX. Pode-se observar a longa duração da força do recorte político-administrativo para a definição de região - bem como do sentido que lhe fora atribuído de periférica em relação à nação -, nas escritas das histórias no presente chamadas de regionais.

\section{A ESCRITA DA HISTÓRIA DE SANTA CATARINA E LUCAS ALEXANDRE BOITEUX}

Ser catarinense não é, somente, nascer em Santa Catarina, é entregar-se totalmente, é enaltecer, pelo trabalho, pela inteligência a Terra Catarinense e isto o fez Lucas Alexandre Boiteux [...] durante toda a sua existência. Para Lucas Alexandre Boiteux, o amor à Terra Catarinense sobreleva em vários tipos de manifestações. [...] Pode-se adentrar na análise de sua obra de historiador, a mais ampla de autor catarinense, onde colocou todo o seu potencial de inteligência, toda a sua capacidade de trabalho, todo o seu método de vida e, a cada passo, estão em realce o homem e a terra catarinense. (Piazza, 1981, p. 31)

Foi pensando originariamente na sua "Santa Terrinha", como chamava Santa Catarina, e na profissão militar que nosso pai iniciou a caminhada para a pesquisa da qual resultaram os seus alentados escritos. A finalidade principal foi desejar saber o que representou o nosso Estado, no âmbito de nossa Pátria, para que se alcançasse o estágio de integração em que se encontra atualmente. (Boiteux, 1981, p. 52, grifo do original)

Os excertos anteriores não deixam margem para dúvidas quanto ao lugar ocupado por Lucas Alexandre Boiteux na escrita da história catarinense: mito fundador de um antes e um depois relacionado à invenção de uma determinada ideia de "cultura catarinense" e, ao mesmo tempo, de uma história integrada à nação, comprometida com o progresso da pátria. Aliás, um dos traços mais fortes que caracterizam Boiteux e sua obra é o patriotismo (Cunha, 1982; Piazza, 1981). Este aparece em diferentes cartas que Boiteux trocava com os colegas sócios do Instituto Histórico e Geográfico de Santa Catarina (IHGSC), ${ }^{7}$ da Academia Catarinense de Letras (ACL) e de outras associações nacionais das quais fazia parte. Marcava presença também na escrita da história, trabalho ao qual ele se propunha.

Filho de pais brasileiros, de descendência franco-suíça por parte de pai e açoriana por parte de mãe, Boiteux nasceu em Nova Trento, Santa Catarina, em 23 de outubro de 1880, e faleceu no Rio de Janeiro, em 16 de dezembro de 1966. Em 1897, com a aprovação nos exames para a Escola Naval, Boiteux iniciaria a

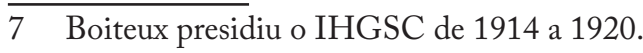


carreira militar, que lhe permitiu alcançar o almirantado (Cunha, 1982; Piazza, 1996). Essa condição o faria passar a maior parte da vida no Rio de Janeiro, com intervalos de alguns anos prestando diferentes serviços à Marinha em Florianópolis (Piazza, 1981, p. 31).

Lucas Alexandre Boiteux pertenceu a uma família de intelectuais e políticos influentes no estado, destacando-se as relações estabelecidas com seu irmão, o advogado e jornalista José Arthur Boiteux, reconhecidamente republicano ainda antes da proclamação da República, fundador do instituto histórico catarinense em 1896, ocupando uma série de cargos públicos importantes no executivo estadual. O próprio Boiteux transitaria entre as questões historiográficas e políticas do estado (por exemplo quando participou da Comissão de Demarcação de Limites entre Santa Catarina e Paraná, nos anos de 1918 a 1922), incluindo aquelas referentes à educação. Ao que consta, chegou até mesmo a ser professor do Ginásio Catarinense, conforme observa Dallabrida (2001, p. 105). Documentos localizados no arquivo do IHGSC também informam a sua participação como avaliador em bancas de exames finais nos grupos escolares e escolas normais do estado na década de 1930 .

A produção histórica de Boiteux foi bastante vasta, e a circulação de seus trabalhos se deu em diferentes lugares. Teve mais de uma centena de artigos publicados em diferentes jornais e revistas locais e nacionais, sendo o mais importante deles o Jornal do Commercio, do Rio de Janeiro, no qual colaborou entre 1911 e 1957 (Cunha, 1982). Preocupava-se em divulgar seus estudos também em diferentes fóruns acadêmicos; em 1914, por exemplo, participou do primeiro Congresso de História Nacional, promovido pelo IHGB. Nesses diferentes espaços, o autor dividia sua produção entre a história catarinense e a história naval.

A publicação do livro Notas para a história catarinense, em 1912, serviu para divulgar a representação da existência de "um espaço" e de "uma gente" catarinenses. A repercussão dessa obra o credenciaria como aquele a quem caberia a responsabilidade de divulgar a história de Santa Catarina nas escolas. No arquivo do IHGSC, encontra-se a súmula do livro encomendado para ser distribuído nas escolas para uso de professores e alunos:

Duas palavras

O ilustrado professor paulista Orestes Guimarães, chamado em boa hora para remodelar a Instrução Pública entre nós, em palestra que entreteve comigo, animou-me a fazer um resumo das minhas - NOTAS PARA A HISTÓRIA CATARINENSE - que servisse não só de guia aos professores na explanação aos alunos como a estes no preparo de suas lições. Embora com o tempo tomado por inúmeros afazeres, dele consegui poupar algumas horas, que foram aplicadas na súmula, que ora apresento. Não sei, francamente, se consegui realizar o desejo do experimentado mestre. Que viesse a satisfazer o escopo prefixado foi a minha intenção ao tentá-lo. Se ela prestar serviço útil à mocidade da minha terra, terei com isso a maior satisfação e largamente compensado o meu trabalho.

Florianópolis, 7 de setembro de 1916. (Boiteux, 1916) 
O texto anterior faz parte da súmula do livro que em 1920 seria publicado com o título de Pequena história catarinense. Datilografado e com algumas anotações a caneta, o documento traz também uma breve introdução sobre a história (que acabou não fazendo parte da versão final do livro), destacando-a como "mestra por excelência" e, nessa direção, capaz de explicar "com clareza e método todas as leis que presidem, encaminham e regem a evolução dos novos na sua marcha vagarosa, mas firme, para o aperfeiçoamento, propinando-se por meio delas exemplos salutares, experiências profundas, incentivos poderosos" (idem, f. 2). Mesmo sendo produto de uma formação histórica inserida no moderno regime de historicidade, ${ }^{8}$ Lucas Alexandre Boiteux parece reiterar o valor da bistoria magistra vitae, concepção clássica da história como fornecedora de lições e exemplos. Esse entendimento da história indica a longa duração de regimes de historicidade e, ao mesmo tempo, que diferentes regimes podem ser sobrepostos, atendendo a necessidades específicas a fim de justificar maneiras de pensar e conceber a história, as relações sociais e de poder contemporâneas dos sujeitos e coletividades que as enunciam.

A publicação do livro Pequena história catarinense foi financiada pelo governo de Santa Catarina para atender às escolas normais e aos quartos anos dos grupos escolares. Fica claro que Boiteux elaborou essa versão didática com base no livro Notas para a história catarinense, principalmente resumindo os textos e acrescentando ilustrações em preto e branco: fotografias, mapas, gravuras e autógrafos de diferentes personalidades políticas conhecidas. O livro de 1912 possuía 436 páginas, e a versão didática, 131 páginas. A dimensão de ambos variou bem pouco, ficando em $14 \times 20$ o primeiro, e $16 \times 23$ o segundo. A Pequena bistória catarinense foi publicada em brochura e sua adoção como obra didática oficial é informada na capa e legitimada pela reprodução, já na abertura do livro, dos decretos assinados pelo governador em exercício à época, Hercílio Luz. Esse processo informa que a escrita, o financiamento e a adoção oficial da Pequena história catarinense remetem para o controle e interferência do estado na história da produção didática, conforme analisou Circe Bittencourt (2008) em suas pesquisas.

Esse mesmo livro seria publicado também pela Editora Melhoramentos, em 1930, com o título de História de Santa Catarina. Resumo didático. Ilustrado e com edição bem cuidada, ele fez parte da série Resumo Didático, que circulou entre

8 Para François Hartog (2013, p. 28), um regime de historicidade pode ser compreendido por meio de duas acepções: uma mais restrita, "como uma sociedade trata seu passado e trata do seu passado"; e uma mais ampla que "serviria para designar a modalidade de consciência de si de uma comunidade humana". Acompanhando as análises de Reinhart Koselleck, Hartog identifica três diferentes regimes de historicidade distintos: história como mestra da vida, que remonta a Cícero, hegemônico até, pelo menos, o século XVIII, e na qual a relação entre passado e futuro é regrada pelo passado; regime moderno de historicidade, instalado entre o final do século XVIII e o início do século XIX (caberia ao futuro esclarecer o passado); e, a partir de 1989, o presentismo instalaria outra ordem do tempo, em que o presente hipertrofiado é, em si mesmo, seu próprio horizonte, sem futuro e sem passado, ou gerando, no presente, o passado e o futuro de que se necessita. 
1918 e 1932 e se dedicava à narrativa da história de um estado brasileiro (Razzini, 2007). Sua leitura era proposta aos alunos das escolas normais e aos professores das escolas primárias. Diferente da Pequena história catarinense, esse livro foi publicado com capa dura, a dimensão um pouco menor (13×18) e 215 páginas. Convém destacar que, embora os capítulos sigam a mesma ordem e possuam quase o mesmo teor, essa edição avançou até 1930 com o tema "Novas administrações".

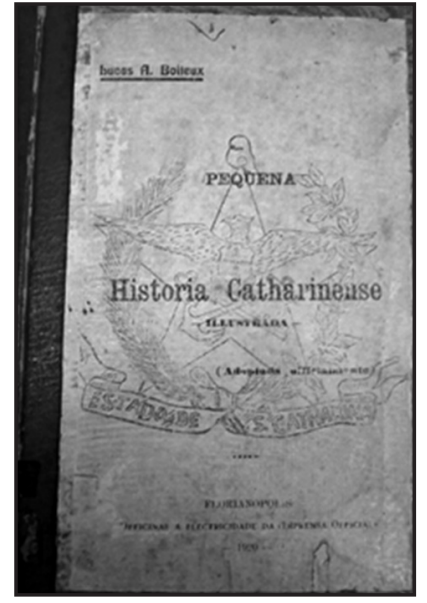

Figura 3 - Capa do livro Pequena bistória catarinense (1920).

Fonte: Acervo do IHGSC.

Elaboração da autora.

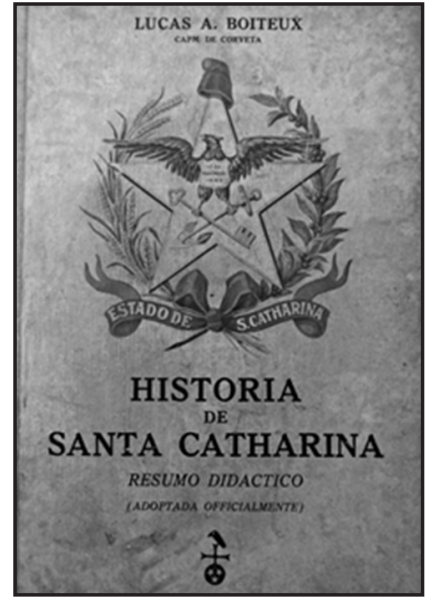

Figura 4 - Capa do livro História de Santa Catarina. Resumo didático (1930).

Fonte: Acervo pessoal da autora. Elaboração da autora.

Boiteux dividia a história em "Universal, Geral e Particular". Baseado nessa divisão, definiu a história de Santa Catarina como uma história particular, "porque só se ocupa da evolução de um estado, da parcela de um povo, qual é o brasileiro" (Boiteux, 1916, f. 3). A noção de "região" adquire nessa definição um caráter particular em relação à nação. Na relação entre geral e particular, a história de Santa Catarina construía-se por uma ideia de história nacional instituída como regra. E, em Boiteux, a narrativa dessa história era sobretudo, patriótica. No prefácio da Pequena história catarinense, datado de 2 de maio de 1919, ele diz:

Como prólogo desejo, apenas, tomar dois trechos d'ouro de Emilio Faguet, ${ }^{9}$ nada mais. Diz ele: "o amor da pequena Pátria é a própria essência do patriotismo, porque a pequena Pátria é a que amamos instintivamente e que não precisa de ser admirável para ser admirada nem de ser amável para ser amada". E: "Pode o historiador não ser um patriota, mas, em que lhe pese, será um semeador de patriotas". Foi assim pensando que me animei a escrever o presente

9 Auguste Émile Faguet (1847-1916), escritor e crítico literário francês, membro da Academia Francesa. 
livrinho. Que a sagrada semente, que procuro difundir, caia em campo feraz é o meu maior anelo. (Boiteux, 1920, p. VII, grifo da autora)

$\mathrm{Na}$ escrita de Boiteux, a história de Santa Catarina só começa após um cuidadoso prolegômeno sobre a história do Brasil, seu passado colonial e seus heróis, para só então partir para os próprios heróis catarinenses. A história regional construída nesse período era feita com a firme disposição de se constituir como parte indissociável da história da nação, servindo aos propósitos de educar para a pátria. A pequena pátria era o caminho para se educar para a grande pátria.

A narrativa apresentada possui diferentes trechos sobre as "bandeiras" e os "bandeirantes", trechos estes que reiteram a representação mítica dessas ações para a formação do território brasileiro e para a formação da raça.

Essas ousadas entradas no sertão resolveram de um modo original todos os problemas vitais do nosso desenvolvimento. $\mathrm{O}$ território pátrio foi grandemente ampliado; suas riquezas naturais ficaram conhecidas [...] Inúmeras povoações devem sua origem às bandeiras, como a fauna, a flora e a geografia o seu conhecimento. Finalmente, grande e benéfico incremento experimentou com elas a formação da raça. (idem, p. 55-56, grifo do original)

Para Kátia Abud (1985), os estudos históricos que tiveram lugar em São Paulo entre 1890 e 1930 evidenciam a tentativa de destacar a importância da região no conjunto da história nacional, e isso foi feito "inventando" simbolicamente os bandeirantes como representantes da força e riqueza de São Paulo. As ações desses homens passavam a ser valorizadas como as responsáveis pelo processo de integração territorial, dando sentido à unidade nacional. Nessa direção, "o bandeirante representava, de um lado, a lealdade ao Estado e de outro a lealdade à nação" (idem, p.132). A apropriação de Boiteux desse sentido atribuído aos bandeirantes - especialmente a Francisco Dias Velho, responsável pela povoação da ilha de Santa Catarina - de certa forma coaduna com a proposta da história regional que ele mesmo buscava operar, uma maneira de inserir o estado nos acontecimentos "relevantes nacionalmente" para a construção da unidade do Brasil.

Ao tratar do "começo" da "terra catarinense", mas especificamente da fundação da primeira vila, a de São Francisco, o autor pondera:

Começava assim a terra catarinense a produzir seus frutos, mostrando sua bondade e pujança, ensaiando novas energias para enfrentar no futuro a formidável competência das suas irmãs que, desde os primeiros tempos, se apresentavam sempre bem aquinhoadas pelas graças da metrópole, dos dois impérios e ainda da república. (Boiteux, 1920, p. 60, grifo da autora)

As preocupações dos políticos e intelectuais catarinenses em relação à integração nacional, bem como aos possíveis ressentimentos sobre a crescente hegemonia do Sudeste, em circulação no início do século XX, marcam presença na escrita de Boiteux sobre o passado. No excerto anterior, chama a atenção o fato de que, ao se 
referir à atenção que as "irmãs" vinham recebendo dos sucessivos governos centrais desde a administração colonial, parece haver certa reivindicação da mesma atenção para a "terra catarinense". Além disso, ao afirmar o caráter de união fraterna entre "as irmãs" - simbolicamente "filhas" da grande pátria -, Boiteux evidencia claramente seu intento de integração ao todo nacional.

Há outra passagem do livro em que os conflitos do presente ficam mais evidentes na representação do passado. Ao narrar a visita de D. Pedro II e Dona Thereza Cristina a Desterro (atual Florianópolis) em 1845, Boiteux (idem, p. 110, grifo da autora) observa:

Os ânimos, agitados pela revolução republicana, não se haviam de todo serenado. A política, essa obsessão maldita do povo brasileiro, separava os catarinenses em duas facções hostis: Partido Liberal e Partido Conservador.

A "revolução republicana" refere-se à chamada Revolução Farroupilha, em 1835, deflagrada no Rio Grande do Sul e espraiada para Santa Catarina, onde foi proclamada a República Juliana, em 1839. No entanto, a contundente crítica à "obsessão maldita do povo brasileiro" pela política pode ser lida também como uma referência às relações políticas nas quais o próprio Boiteux estava inserido - como parte de uma família proeminente e como voz autorizada a emitir opinião sobre questões relacionadas ao estado. As primeiras décadas do século $\mathrm{XX}$ foram marcadas nacionalmente (e em Santa Catarina não foi diferente) por disputas de poder entre os estados e o governo central. Foi também um período de redefinição das relações de autoridade entre os grupos locais, o que acarretou embates, disputas e tensões internas. No estado, ao lado dessas questões, juntavam-se as fraturas resultantes dos conflitos da Revolução Federalista, ${ }^{10}$ em 1893, e da Guerra do Contestado, ${ }^{11}$ em 1912. Importante lembrar que, se esses conflitos haviam angariado uma onda nacionalista de pertença e de integração social e territorial no estado, também fazia emergir igualmente outras inquietações consoantes a tal processo.

Nessa direção, é importante ressaltar que a obra historiográfica de Boiteux relativa a Santa Catarina demarca um investimento político na construção de uma identidade catarinense que precisou lidar com dois movimentos distintos e complementares em pauta naquele momento. $\mathrm{O}$ primeiro dizia respeito à configuração

10 É como tem sido chamado o longo ciclo de conflitos armados que se estendeu do ano 1893 a 1895, abrangendo os estados do Rio Grande do Sul, Santa Catarina e Paraná. A partir de setembro de 1893, o movimento foi realimentado pela Revolta da Armada na Baía de Guanabara, passando a ter repercussões no estado do Rio de Janeiro e no Distrito Federal (Franco, 1993).

11 Conflito social armado motivado por disputas pela terra, entre outras questões, que colocou de um lado posseiros, pequenos lavradores, ervateiros, tropeiros e agregados e de outro, coronéis, grandes fazendeiros e representantes do poder estadual e federal, entre 1912 e 1916. Nomeia-se "Contestado" por ter ocorrido numa extensa região de planalto na divisa entre Santa Catarina e Paraná, cuja jurisdição era disputada pelos dois estados (Machado, 2004). 
populacional de Santa Catarina, marcada pela diversidade cultural em razão do grande contingente de imigrantes estrangeiros. Essa diversidade muitas vezes aparecia, nos debates que envolviam políticos e intelectuais do estado, como a responsável pela falta de uma denominada "cultura catarinense". Além disso, essa questão vinha sendo alvo de constante preocupação de intelectuais, autoridades públicas e instituições desde o fim do século XIX. Luiz Felipe Falcão (2000, p. 72) chama a atenção, por exemplo, para o fato de o jornal oficial do Partido Republicano Catarinense (PRC), que esteve à frente do governo do estado até 1930, ter encampado clara campanha sobre o tema, ao incluir em sua pauta a publicação de "desmentidos formais e artigos com a finalidade de conjurar o 'perigo alemão" no estado. O segundo ponto, complementar ao primeiro, dizia respeito ao problema do "regionalismo". Isso significava que a afirmação da brasilidade de Santa Catarina passava pela construção de uma identidade catarinense, mas também precisava lidar com o problema da unidade diante das histórias regionais, atualizada principalmente pelas oligarquias regionais nas primeiras décadas do regime republicano (Diniz Filho; Bessa, 1995).

Seguramente, Lucas Alexandre Boiteux foi quem primeiro apresentou esforço de síntese de uma história para Santa Catarina e é legitimado por seus pares como aquele que, em seu tempo, melhor a conhecia e a divulgou (Piazza, 1981, 1996). Pode-se dizer que, além da escrita e divulgação da história catarinense, Boiteux alcançou um dos objetivos mais caros com sua obra: definir o que seria catarinense e integrar o estado ao conjunto da história nacional. Faz-se importante ressaltar que tanto a escrita quanto o ensino da "história pátria" são centrais para se compreender a articulação entre história nacional e história regional na construção da nação republicana. A percepção de que a história das regiões só seria possível se estas assegurassem sua lealdade à unidade nacional foi um importante elo da corrente republicana no duplo processo de formação de cidadãos e construção de um projeto de futuro coletivo associado à imagem de nação moderna e civilizada.

\section{NAÇÃO E REGIÃO: ALGUMAS QUESTÕES À GUISA DE CONSIDERAÇÕES FINAIS}

No regime republicano, a busca pela unidade nacional, ancorada nos conceitos de nação, estado e pátria, precisava ainda incluir o povo. A resolução dessa equação seria fundamental para o projeto de comunidade imaginada ${ }^{12}$ que se pretendia construir a partir de então. Mas essa busca, como muitas outras inerentes ao processo de construção do Estado-nação, precisou considerar e contrapor, de modo imperativo, as significativas tendências regionais que se apresentavam na imensidão do território reconhecido como brasileiro. A história, sobretudo aquela escrita com

12 Expressão emprestada de Benedict Anderson (1989, p. 14), que define nação como "uma comunidade politicamente imaginada". 
a responsabilidade do IHGB e seus congêneres, serviria ao propósito de legitimação das fronteiras estabelecidas entre os estados, bem como da construção de passado e tradição comuns, que destacassem as especificidades de cada região e sua respectiva contribuição para a grandeza da nação. Instaurava-se aí um discurso, que teve longa duração, o qual estabelecia uma clara hierarquia da nação em relação à região, que, por sua vez, também posicionaria as identidades nacionais como normativas e hegemônicas e as regionais como desviantes e secundárias, numa operação marcada pela "metanarrativa hegemônica da nação" (Weinstein, 2003, p. 23).

A divisão hierárquica entre nação e região implicaria a própria definição de história regional separada da história nacional. A história que hoje denominamos de "regional" foi definida com influência do IHGB e seus congêneres provinciais e, depois, estaduais. Segundo Marcos Lobato Martins (2010, p. 140-141), inicialmente a história regional configurava-se como uma corografia, ou seja, uma monografia municipal ou estadual que mistura história, tradição e memória coletiva (as corografias "tomavam como fundamento espaços bem recortados politicamente, que eram estudados em si mesmos"). Dessa maneira, a relação entre regional e nacional reduzia-se à descrição de grandes acontecimentos da história do Brasil e de seu impacto nos estados. Além disso, as corografias estabeleciam frágil (às vezes inexistente) articulação entre geografia e história, ou entre as dimensões micro e macroespaciais; caracterizavam-se também pelo viés laudatório e pelo patriotismo ufanista (idem, p. 141). Apesar disso, é certo que as corografias acabaram se tornando fontes de consultas para a elaboração de materiais didáticos a serem usados nas escolas primárias, quando da necessidade de se estudar aspectos da história da cidade ou mesmo do estado.

Com o passar do tempo, a história regional foi sendo materializada como a história de cada estado. Contudo, estudar a história regional com base nesse recorte político e administrativo reifica o discurso hegemônico e excludente que legitimou a organização de uma história nacional. Além disso, ignora que a construção histórica de uma região, mesmo se localizada espacialmente, precisa considerar outras dimensões desse espaço que não apenas a administrativa, política ou econômica. A obra de Boiteux precisa ser lida nessa clave, no sentido de que é devedora das corografias em muitos aspectos, bem como da noção de região e nação construída pela historiografia do século XIX.

Grosso modo, pode-se resumir que João Ribeiro tentou explicar o Brasil pelas diferenças entre os povos e regiões, a fim de legitimar a ideia de unidade, e Boiteux partiu da ideia de unidade para então explicar Santa Catarina e seu lugar e lealdade à nação. Mas a escrita da história de Santa Catarina não é o único exemplo em que essa dinâmica fica evidente. A história mostra que os movimentos que buscam reforçar a identidade regional não necessariamente estariam relacionados com a oposição à unidade nacional. A pesquisadora Anne-Marie Thiesse (2009), ao analisar, na França da Terceira República (1870-1940), a relação entre regionalismo e nacionalismo, observa que o movimento regionalista francês, embora lutasse contra o centralismo estatal, certamente não se desenvolveu contra a unidade francesa, pois: 
O regionalismo correspondia a uma representação da nação como um conjunto de diversidades complementares. "A unidade (nacional) é rica por suas diversidades (regionais)": esta fórmula foi muito utilizada na época pelos países que atingiam a última fase do processo da construção nacional. Dessa forma, a unidade estando bem consolidada, a diversidade poderia retomar seu lugar, sendo a ela subordinada. Insistir sobre a complementaridade das diversidades geográficas era também uma maneira eficaz de "pacificar" a sociedade, sugerindo que as diferenças sociais, também, fossem complementares e não devessem, portanto, suscitar antagonismos. (idem, p. 15)

Pode-se dizer que a escrita da história do Brasil baseada nas histórias ditas regionais está em consonância com o modelo da história francesa, na qual também o regionalismo desempenhou um papel de consolidação da identidade nacional. Deve-se destacar ainda que não foi apenas a história de Santa Catarina, no início do século XX, que assimilou esse modelo. Também os rio-grandenses historicamente conceberam seu pertencimento à nacionalidade brasileira por esse mesmo parâmetro, conforme aponta a pesquisa de Alexandre Lazzari (2004).

Faz-se importante destacar outro movimento observado nas décadas de 1960 e 1970, quando a produção historiográfica brasileira em nível de pós-graduação estava quase que toda concentrada no eixo Rio-São Paulo. Nesse período, observa-se a valorização das histórias paulista e fluminense como história nacional, sendo os demais estados portadores de uma história regional. À medida que os programas de pós-graduação foram se multiplicando no Brasil, sobretudo após a década de 1970, as pesquisas sobre história regional se impuseram, trazendo consigo preocupações, mas também novas possibilidades de análise sobre o que seria a história regional, qual lugar ela ocupava e quais relações estabelecia com a história nacional.

Janaína Amado, na apresentação da coletânea República em migalhas: história regional e local (1990), chama a atenção para o crescente interesse dos historiadores pela questão, indicado pelo próprio conjunto de artigos reunidos no livro, todos dedicados à "história" e "região". Esse interesse pela questão regional coincidia com o momento em que o conceito de região estava sendo problematizado, passando por profundas transformações propostas principalmente pelos geógrafos (idem, p. 7-8).

Por meio dessa influência, muitos estudos, inclusive os constantes no livro, definiam região como uma "categoria espacial que expressa uma especificidade, uma singularidade, dentro de uma totalidade; assim, a região configura um espaço particular dentro de uma determinada organização social mais ampla, com a qual se articula" (idem, p. 8). Barbara Weinstein (2003, p. 25) afirma, porém, que, mesmo que esses trabalhos - aos quais Janaína Amado fazia referência - tenham inserido a história regional em uma narrativa histórica mais abrangente, eles ainda aceitaram certa fixidez das categorias, bem como a estabilidade das fronteiras entre a região e a nação. O sentido de particular e geral, por exemplo, usado na introdução de Janaína Amado para estabelecer a relação entre nação e região, é bastante próximo daquele definido por Lucas Alexandre Boiteux, em 1916, conforme já tratado neste 
artigo. Nesse sentido, deve-se reconhecer que, se os sentidos de nação e região mudaram desde as primeiras décadas do século $\mathrm{XX}$, eles não deixaram de reafirmar o paradigma narrativo eurocêntrico da nacionalidade. Ou seja, a identidade nacional estaria presa ao modelo de inexorabilidade do progresso e civilização, que, por sua vez, legitimou a invenção dos modernos estados nacionais e o colonialismo. Esse mesmo paradigma parece estar na base da própria construção de uma ideia de história regional separada da história nacional.

Barbara Weinstein (2003) estabelece um diálogo bastante instigante com Prasenjit Duara (1996), o qual se retoma aqui. Para esse historiador indiano, a narrativa eurocêntrica da nação situa-se na oposição entre império e nação/modernidade, e entre centro e periferia (Duara, 1996, p. 151), o que abre pouco espaço para perceber que as identidades nacionais, ainda que inventadas, somente se constroem em relação às identidades locais. Para esse pesquisador, o nacionalismo raramente é o nacionalismo da nação, num sentido abrangente de pertença; com maior frequência, ele é reconfigurado sempre com base no local, em que visões muito diferentes sobre o nacional concorrem e negociam umas com as outras. Para Duara (idem, p. 153), mesmo a expressão comunidade imaginada de Benedict Anderson (1989) ou a ideia de consciência nacional de Ernest Gellner (1983) seriam equivocadas, pois residiriam no postulado geral de uma subjetividade coesa, quando indivíduos e grupos, na verdade, identificam-se simultaneamente com diversas comunidades, que são todas imaginárias; essas identificações são historicamente mutáveis e, muitas vezes, conflituosas entre si.

Como professor e intelectual de seu tempo, João Ribeiro colocou no cerne de seu trabalho o problema de "quem somos". Ao formular a resposta dessa simbólica questão, Ribeiro legou à história do Brasil, e ao seu ensino, marcos referenciais - de longa duração - sobre a identidade nacional, “o povo brasileiro", e apontou o lugar que as histórias regionais poderiam ocupar na escrita da história nacional. Lucas Alexandre Boiteux não incorpora as inovações historiográficas de João Ribeiro, mas isso não é o mais importante. A questão principal é que a narrativa elaborada por Boiteux incorpora a ideia de que o regional, a "pequena pátria", são representações mobilizadas para integrar o estado ao todo nacional, numa relação de articulação que pressupõe um nível hierárquico bastante claro. Entretanto, mesmo usando parâmetros diferentes daqueles adotados por Ribeiro, Boiteux contribuiu para a reiteração de um paradigma poderoso das relações entre centro e periferia, entre nação e região, e que guardam certa estabilidade ainda no presente.

O nacionalismo constitui um dos elementos mais permanentes na matriz disciplinar da história escolar e, recriado em diferentes contextos, é certo que segue comparecendo nos programas curriculares, nos livros didáticos, na rotina do ensino de história. A invenção de uma terra e de uma gente identificadas como "catarinense" replicou as noções de centro/periferia, observadas na configuração do sentido de nação na narrativa de Boiteux.

Se, no limiar do século XXI, a questão da unidade nacional não parece mais ser um problema, permanecem abertas, no presente, as questões relativas ao lugar 
ocupado pela história denominada como regional ou local na escrita e no ensino da história do Brasil. No tempo de Ribeiro e Boiteux, escrever a história, divulgá-la, era um dever cívico e pedagógico. Os livros didáticos e, a partir das primeiras décadas do século XX, também os jornais e revistas acabaram por se tornar veículos poderosos de divulgação de valores relacionados à ideia de civilização e de nação. No presente, assiste-se à ampliação da demanda por histórias regionais na educação básica, sobretudo com a avaliação, compra e distribuição de obras didáticas definidas como regionais pelo Programa Nacional do Livro Didático (PNLD) para o quarto ou quinto ano do ensino fundamental. Nessas obras, a história local e/ou regional é a história dos estados brasileiros, e as identidades sociais, autoevidentes, primeiramente se conectam aos estados para, a partir daí, compor a própria identidade nacional. A narrativa de uma nacionalidade portadora do progresso, amparada numa relação hierárquica e excludente, estabeleceu padrões de inteligibilidade que ocultaram as identidades regionais como constituidoras da nação e da nacionalidade, num sentido amplo e articulado, sem hierarquias de importância e relevância. Concordando com Barbara Weinstein (2003), resta à historiografia do presente o desafio de escrever e divulgar uma história nacional "regional".

\section{REFERÊNCIAS}

Aвud, Kátia Maria. O sangue Itimorato e as nobilíssimas tradições: a construção de um símbolo paulista: o bandeirante. 1985. 342f. Tese (Doutorado em História Social) Universidade de São Paulo, São Paulo, 1985.

Amado, Janaína. História e região: reconhecendo e construindo espaços. In: Silva, Marcos Antônio da (Coord.). República em migalhas: história regional e local. São Paulo: Marco Zero/CNPq, 1990, p. 6-15.

Anderson, Benedict. Nação e consciência nacional. São Paulo: Ática, 1989.

Araripe Júnior, Tristão de Alencar. Prefácio. In: Ribeiro, João. História do Brasil. Curso Superior. 2. ed. Rio de Janeiro: Livraria Cruz Coutinho de Jacintho Ribeiro dos Santos, Editor, 1901. p. V-XVI.

Berstein, Serge. A cultura política. In: Rioux, Jean-Pierre; Sirinelli, Jean-François (Orgs.). Para uma bistória cultural. Lisboa: Estampa, 1998. p. 349-363.

Bittencourt, Circe. Livro didático e saber escolar (1810-1910). Belo Horizonte: Autêntica, 2008.

Boiteux, Lucas Alexandre. Notas para a história catarinense. Florianópolis: Tipografia a vapor da Livraria Moderna, 1912.

Súmula. Florianópolis: Acervo do Instituto Histórico e Geográfico de Santa Catarina, 1916. (Coleção Lucas Alexandre Boiteux).

Pequena história catarinense. Ilustrada. Florianópolis: Oficinas a eletricidade da Imprensa Oficial, 1920. 
História de Santa Catarina. Resumo didático. São Paulo: Companhia Melhoramentos, 1930.

Boiteux, Nelson Demaria. Agradecimento. In: Santa Catarina (Estado). Aspectos da vida e da obra de Lucas Alexandre Boiteux. Florianópolis: Conselho Estadual de Cultura, 1981.p. 47-55.

Certeau, Michel de. A escrita da história. Rio de Janeiro: Forense Universitária, 1982.

Chartier, Roger. A história cultural. Entre práticas e representações. 2. ed. Tradução de Maria Manuela Galhardo. Algés, Portugal: Difel, 2002.

Cunha, Maria Teresa Santos. A contribuição historiográfica de Lucas Alexandre Boiteux no Jornal do Comércio do Rio de Janeiro (1911-1957). 1982.313f. Dissertação (Mestrado em História) - Universidade Federal de Santa Catarina, Florianópolis, 1982.

Dallabrida, Norberto. A fabricação escolar das elites: o Ginásio Catarinense na Primeira República. Florianópolis: Editora Cidade Futura, 2001.

Diniz Filho, Luis Lopes; Bessa, Vagner de Carvalho. Território e política: as mutações do discurso regionalista no Brasil. Estudos Históricos, Rio de Janeiro: FGV/CPDOC, v. 8, n.15, p. 27-37, 1995.

Duara, Prasenjit. Historicizing national identity, or who imagines what an when. In: Eley, Geoff; Suny, Ronald Grigor (Orgs.). Becoming national: a reader. New York: Oxford University Press, 1996. p. 151-177.

Falcão, Luiz Felipe. Entre ontem e amanhã: diferença cultural, tensões sociais e separatismo em Santa Catarina no século XX. Itajaí: Editora da Univali, 2000.

Franco, Sérgio da Costa. A Guerra Civil de 1893. Porto Alegre, Editora da UFRGS, 1993.

Gasparello, Arlette Medeiros. Construtores de identidades: a pedagogia da nação na escola secundária brasileira. São Paulo: Iglu, 2004.

Gellner, Ernest. Nações e nacionalismo. Tradução de Inês Vaz Pinto. Lisboa: Gradiva, 1983.

Gomes, Ângela de Castro. José Veríssimo e a educação nacional: história pátria e cultura política republicana. In: Cury, Cláudia Engler; Flores, Elio Chaves; Cordeiro Júnior. Raimundo Barroso (Orgs.). Cultura histórica e historiografia. João Pessoa: Editora Universitária/UFPB, 2010. p.147-157.

Guimarães, Manoel Luís Salgado. Nação e civilização nos trópicos: o Instituto Histórico e Geográfico Brasileiro e o projeto de uma história nacional. Estudos Históricos, Rio de Janeiro: FGV/CPDOC, n. 1, p. 5-27, 1988.

Hallewell, Laurence. O livro no Brasil: sua história. 2. ed. revista e ampliada. Tradução de Maria da Penha Villalobos et al. São Paulo: Edusp, 2005.

Hansen, Patrícia Santos. Feições e fisionomia: a história do Brasil de João Ribeiro. Rio de Janeiro: Access, 2000. 
Hartog, François. Regimes de historicidade: presentismo e experiências do tempo. Belo Horizonte: Autêntica, 2013.

Hoвsваwm, Eric John. Naçôes e nacionalismo desde 1780 - programa, mito e realidade. Tradução de Maria Celia Paoli e Anna Maria Quirino. 4. ed. Rio de Janeiro: Paz e Terra, 1990.

Hollanda, Guy de. Um quarto de século de programas e compêndios de história para o ensino secundário brasileiro (1931-1956). Rio de Janeiro: Instituto Nacional de Estudos Pedagógicos/Ministério da Educação e Cultura, 1957.

LAzzAri, Alexandre. Entre a grande e a pequena pátria: letrados, identidade gaúcha e nacionalidade (1860-1910). 2004. 363f. Tese (Doutorado em História) - Universidade Estadual de Campinas (UNICAMP), Campinas, 2004.

Le Goff, Jacques. História e memória. 5. ed. Tradução de Irene Ferreira et al. Campinas: UNICAMP, 2003.

Machado, Paulo Pinheiro. Lideranças do Contestado. Campinas: Editora da UNICAMP, 2004.

Martins, Marcos Lobato. História regional. In: Pinsky, Carla Bassanezi (Org.). Novos temas nas aulas de história. 2. ed. São Paulo: Contexto, 2010. p. 135-152.

Martius, Karl Friedrich Philipp von. Como se deve escrever a história do Brasil. Revista Trimestral de História e Geografia. Rio de Janeiro: IHGB - t. 6, v. 6, n. 24, p. 381-403, jan. 1845.

Melo, Ciro Flávio de Castro Bandeira de. Senhores da história e do esquecimento: a construção do Brasil em dois manuais didáticos de história na segunda metade do século XIX. Belo Horizonte: Argvmentvm, 2008.

Nava, Pedro. Chão de ferro. São Paulo: Ateliê Editorial; Giordano, 2001. (Memórias, v.3). Piazza, Walter. Catarinensismo. In: Sanra Catarina (Estado). Aspectos da vida e da obra de Lucas Alexandre Boiteux. Florianópolis: Conselho Estadual de Cultura, 1981.

Instituto Histórico e Geográfico de Santa Catarina: estudo histórico-analítico (1896-1996). Florianópolis: UDESC, 1996.

Razzini, Márcia de Paula Gregório. A produção de livros escolares da Editora Melhoramentos na Primeira República. In: Congresso Brasileiro de Ciências da Comunicação - Intercom, 30., 2007, Santos. Anais eletrônicos... Santos: Intercom, 2007. Disponível em: <http://www.adtevento.com.br/intercom/2007/resumos/R1479-2. pdf $>$. Acesso em: 12 mar. 2012.

Ribeiro, João. História do Brasil. Curso superior. 2. ed. Rio de Janeiro: Livraria Cruz Coutinho de Jacintho Ribeiro dos Santos, Editor, 1901.

História do Brasil. Curso superior. 18. ed. Edição revista e completada por Joaquim Ribeiro. Rio de Janeiro: Livraria Francisco Alves e Companhia, 1966.

Ricoeur, Paul. Tempo e narrativa. A intriga e a narrativa histórica. v. 1. São Paulo: Editora WMF; Martins Fontes, 2010. 
Thiesse, Anne-Marie. Ensinar a nação pela região: o exemplo da Terceira República Francesa. Educação, Santa Maria: UFSM, v. 34, n. 1, p. 13-28, jan./abr. 2009.

Weinstein, Barbara. Regional vs national history: rethinking categories from a comparative perspective. Território e fronteiras, Cuiabá: UFMT, v. 4, n. 1, p. 23-31, jan./ jun., 2003.

\section{SOBRE A AUTORA}

Cristiani Bereta da Silva é doutora em história pela Universidade Federal de Santa Catarina (UFSC). Professora da Universidade do Estado de Santa Catarina (UDESC).

E-mail: cristianibereta@gmail.com 